\title{
Development of On-line Roll Grinding System for Hot Strip Mill
}

\author{
Kanji HAYASHI, Hiroaki SHIMAZUTSU ${ }^{1)}$ and Junichi NISHIZAKI ${ }^{2)}$
}

Hiroshima Machinery Works, Mitsubishi Heavy Industries, Ltd., Kan-on-shin-machi, Nishi-ku, Hiroshima, Hiroshima-ken, 733 Japan. 1) Hiroshima R \& D Center, Mitsubishi Heavy Industries, Ltd., Kan-on-shin-machi, Nishi-ku, Hiroshima, Hiroshima-ken, 733 Japan.

2) System Engineering Department, Mitsubishi Heavy Industries, Ltd., Kan-on-shin-machi, Nishi-ku, Hiroshima, Hiroshima-ken, 733 Japan.

(Received on October 17, 1990; accepted in final form on January 25, 1991)

\begin{abstract}
Schedule Free-Rolling (SFR), which means rolling with unrestricted rolling schedules in the processing of strips of various materials and widths, should be developed to realize hot-charge-rolling and hot-direct-rolling whose importance has been increasing in hot strip rolling mills. As a technique to make SFR practical, we have developed a non-driven cup type On-line Roll Grinder (ORG) which smooths the wear of a work roll on line. Our experiments have proven that the ORG has the basic capabilities required for an on-line roll grinder: high grinding capacity, long grinding wheel life and appropriate roughness of the finished surface. In addition, the ORG is free of welding and dulling and maintains stable grinding characteristics for a long time. We have also developed an on-line roll grinding system equipped with an On-line roll Profile Meter which can measure the profile of a revolving roll without contact. The data taken by these profile meters is fed back to the ORG, thereby increasing its grinding accuracy and allowing it to grind a roll to the required profile.
\end{abstract}

KEY WORDS: hot strip mill; schedule-free-rolling; roll wear; on-line roll grinder; roll profile meter; feedback grinding.

\section{Introduction}

Emphasis is now being given to upgrading the controllability of strip crown and shape in the Hot Strip Mill (HSM), to achieve high accuracy and to connect the HSM directly with upstream processes in the production of various quality products at low cost.

A variety of new models of rolling mills have already been developed to improve and perfect the capability of controlling strip crown and shape with the development of a computer-aided control system. Realization of a direct connection with upstream processes requires Schedule Free Rolling (SFR) which can relax restrictions on the Rolling Schedule, such as materials and strip width. For this, it is essential to ensure the smoothing of work roll wear as well as sufficient crown controllability.

The On-line Roll Grinder (ORG) is a machine with grinders directly installed in a rolling mill which conduct corrective grinding of the work roll surface during rolling operations, thus maintaining an appropriate roll shape at all times. This is a new technology which has gained the attention and high expectations of the steel industry due to its great effect on quality improvement of rolled products, realization of SFR and the extension of replacement intervals for rolls, all of which contribute to excellent productivity and substantial energy savings.

To meet the demand for a technology which can cope with wear and surface roughness of rolls for hot rolling, we originally designed a non-driven cup-type ORG, and tested the device using actual machine size apparatus under conditions simulating an actual operating environment; the excellent performance of the ORG was confirmed.

The device is mounted with an On-line roll Profile Meter (OPM) which can measure a roll in rotation without any contact, aiming at higher grinding accuracy. Utilizing this meter, an on-line roll grinding system to grind a roll into the required shape from feedback of the measured data was developed.

This report explains the principles and characteristics of these devices, the accuracy of roll profile measurement and the test results of feedback grinding accuracy.

\section{Principles and Basic Characteristics of ORG Grinding}

\subsection{Grinding Principles and Characteristics}

Figure 1 shows the principles of ORG grinding. The grinding wheel has a cup shape and its rotation axis is not driven forcibly, but is supported by bearings alone. The mechanical feature is that the axis of rotation is inclined against the line normal to the work roll surface by a given small angle $\alpha$, and is installed so that it can be shifted from the roll axis by a given offset value, $H$.

When the cup-type grinding wheels are pressed on the outer surface of a roll with a given force in these positions, the small angular inclination forces the wheels to rotate in a given direction with the rotation of the roll. Here, the roll and the grinding wheels make a line contact, establishing a difference in velocity vectors between roll $\left(V_{R}\right)$ and grinding wheel $\left(V_{G}\right)$ which allows the grinding operation.

Thus, without being forcibly driven, the grinding wheel can follow the rotation of the roll to perform the grinding operation; this is the greatest feature of our system and makes the apparatus compact and simple so that it can be installed in any rolling mill. The grinding characteristics shown below can also be expected.

(1) Since the grinding wheel rotates and grinds constantly shifting the line of contact, the same part of this wheel is not 
in continuous use, so that welding or dulling on the surface of the wheel does not occur.

(2) Because of the various directions of speed vectors on the line of contact, as explained later, grinding is realized in a direction crossing the preceding grinding pass. Therefore, the trajectory of abrasive grains does not trace the same groove of the preceding pass, allowing superior grinding capability.

(3) With the existing grinding method, a grinding wheel with fine abrasive grain size cannot be used due to problems of welding or dulling, whereas this method causes little welding or dulling as explained in (1) above; therefore, a grinding wheel of finer grain size can be used, allowing finishing with a finer roll surface.

(4) Since the grinding wheel with a harder bond grade

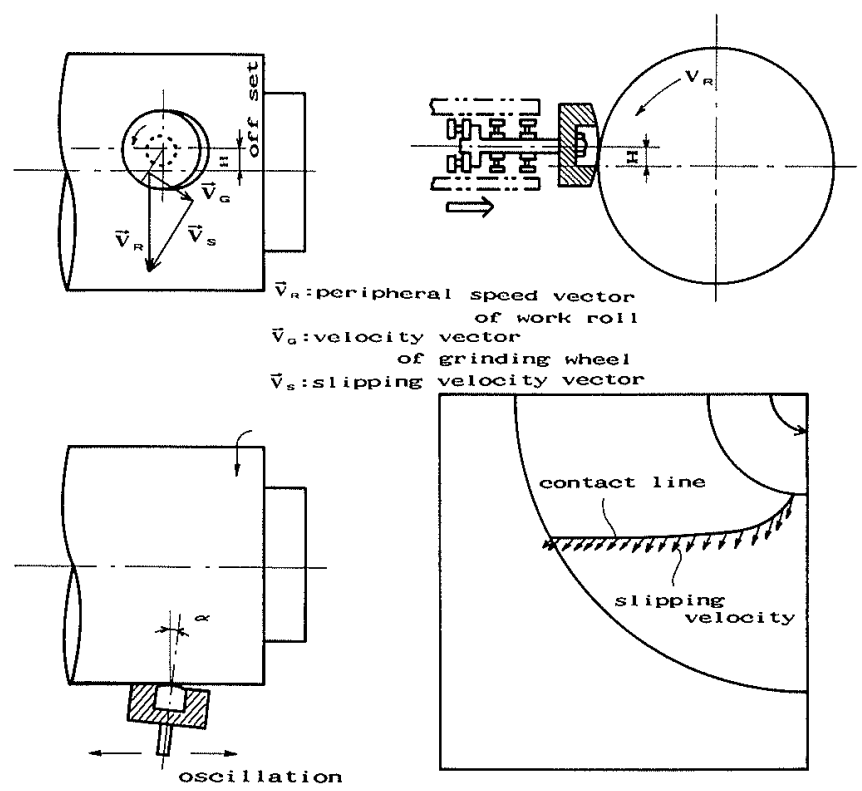

Fig. 1. Principles of $O R G$.
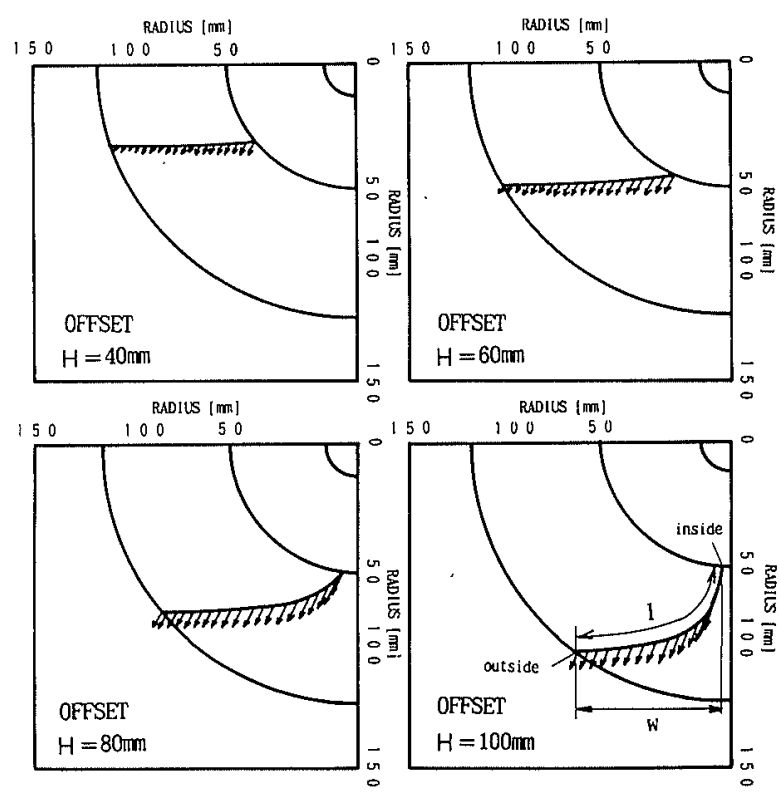

Fig. 2. Relationships between slipping velocity vector and offset of grinding wheel. can be used for the reasons stated in (3), the life of the grinding wheel can be prolonged.

\subsection{Rationalization of Offset Value by analyzing Contact Conditions of the Grinding Wheel}

To examine the effect of offset value, which is a characteristic of this grinding system, analysis was made of the contact form of the grinding wheel and velocity vectors.

The method used for this analysis is explained in Appendix.

As a typical illustration of this analysis, Figs. 2 and $\mathbf{3}$ show changes in the contact form and rotation speed of the grinding wheel and in slipping velocity when the offset value is varied.

If the offset value $(H)$ increases,

(1) Direction of slipping speed becomes uniform, and approaches the direction of peripheral speed of the roll.

(2) Overlapping of vectors can be seen at the inside circumference of the grinding wheel.

(3) Uneven wear ( $\delta$ max.) of the grinding wheel is in creased.

(4) The width of contact $(W)$ of the grinding wheel becomes maximum at $H=60 \mathrm{~mm}$, and declines thereafter.

(5) The slipping speed $\left(V_{S}\right)$ increases.

From the viewpoint of grinding performance, the greater the slipping speed, the better the results. But in order to smooth the roll surface it is preferable that the width of contact is wider. In order to prevent welding of the grinding wheel, it would be necessary to avoid areas where the slipping speed vectors overlap on the inside circumference of this wheel. Taking all these factors integrally, the most appropriate offset value is judged to be between 50 and $70 \mathrm{~mm}$.

Since the contact condition of the grinding wheel varies with the offset value, in the ORG the offset value is adjusted to be stable despite changes in the roll diameter and the central axis height of the roll.

\subsection{Basic Grinding Characteristics}

Since ORG has a lower rotating speed than conventional grinders and the grinding wheel is not forcibly driven, understanding of the grinding characteristics is important. In

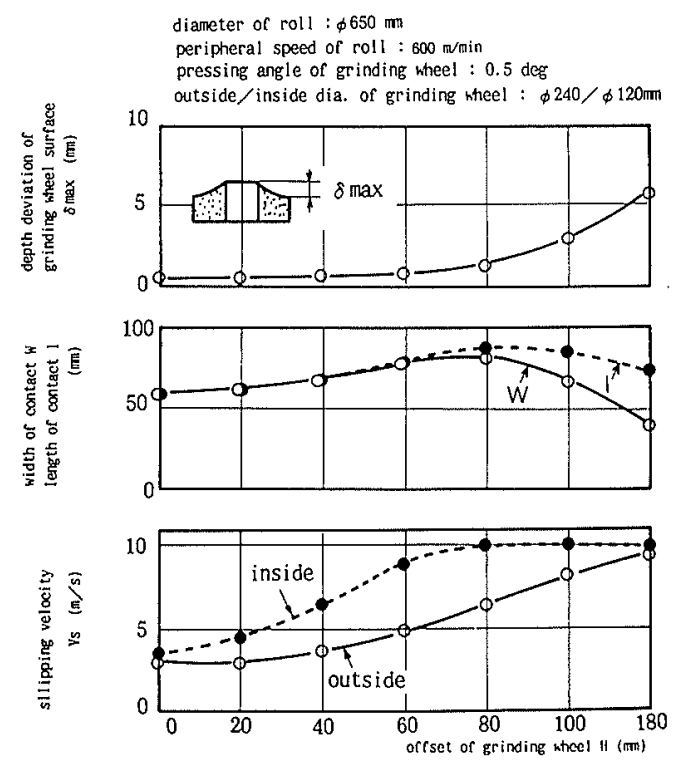

Fig. 3. Relationships between specifications of ORG and offset of grinding wheel. 
addition, regeneration of the grinding wheel (dressing) is not possible during grinding operations once the wheel has been installed. Thus, it is essential to maintain a stable grinding performance for the life of the grinding wheel. Experiments were then conducted to verify these basic characteristics.

\subsubsection{Experimental Apparatus and Conditions}

Figure 4 is a schematic drawing of the experimental apparatus, and Table 1 lists the main specifications.

The experimental conditions were set up by actuators as shown in Table 2.

\subsubsection{Basic Characteristics}

As shown in Fig.5, a single grinding wheel was used to partially grind a roll. The depth of grinding $R$ was determined from the difference in roll profile before and after the operation. Grinding performance was evaluated by examining the depth of grinding per each single rotation of the roll $v_{\mathrm{g}}$, as shown in Eq. (1).

Life of a grinding wheel was evaluated by calculating the grinding ratio $G$, i.e., the ratio of ground volume of the roll to worn volume of the wheel, as shown in Eq. (2).

$$
v_{g}=\frac{\Delta R \times L_{o}}{W \times t_{g} \times N}=\frac{\Delta R \times L_{0} \times \pi \times D_{w^{\prime}} \times 60}{W \times t_{g} \times V_{R} \times 10^{3}} \ldots
$$

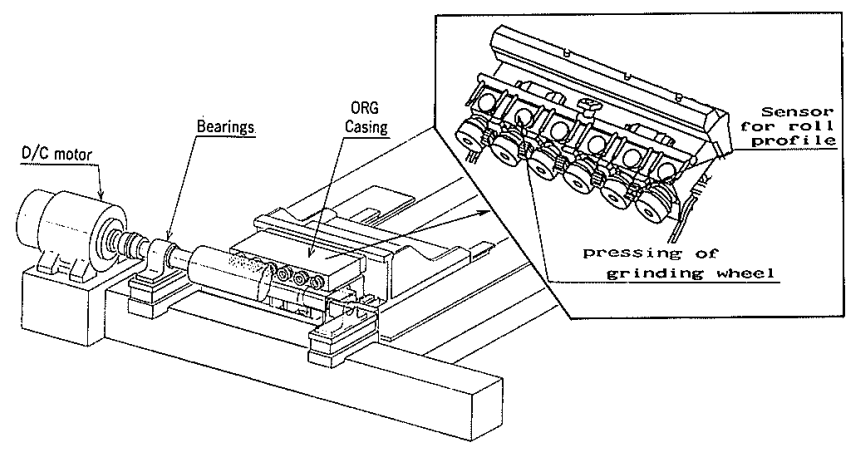

Fig. 4. Schematic drawing of the experimental apparatus.

Table 1. Major specification of full-scale test machine.

\begin{tabular}{|c|c|}
\hline Item & Specification \\
\hline Roll size & $\phi 600 \times 11800 \mathrm{~mm}$ \\
\hline Driving motor & $\mathrm{DC} 300 \mathrm{~kW}$ \\
\hline No. of grinder heads & 6 \\
\hline Grinding force & $0-2500 \mathrm{~N}$ \\
\hline Oscillation length & $\max .300 \mathrm{~mm}$ \\
\hline Oscillation speed & $\max .200 \mathrm{~mm} / \mathrm{s}$ \\
\hline
\end{tabular}

Table 2. Experimental condition.

\begin{tabular}{lcc}
\hline & Item & Condition \\
\hline Roll material & & Nickel grain cast iron \\
Peripheral speed of work roll & $400-750 \mathrm{~m} / \mathrm{min}$ \\
Grinding wheel & Material & $\mathrm{GC}$ \\
& Grain size & 320 \\
& Bond grade & $\mathrm{K}$ \\
Grinding force & & $600 \mathrm{to} 1760 \mathrm{~N}$ \\
Offset length & $60 \mathrm{~mm}$ \\
Oscillation length & $295 \mathrm{~mm}$ \\
Oscillation speed & $60 \mathrm{~mm} / \mathrm{s}$ \\
\hline
\end{tabular}

$$
G=\frac{\Delta R \times \pi \times D_{w} \times L_{0}}{V \times 10^{3}}=\frac{\Delta R \times \pi \times D_{w^{\prime}} \times L_{0}}{w_{g} \times \pi \times\left(D^{2}-d^{2}\right) / 4}
$$

where, $D$ : Outer dia. of grinding wheel $(\mathrm{mm})$

$d$ : Inner dia. of grinding wheel (mm)

$D_{w}$ : Roll diameter (mm)

$L_{o}:$ Oscillation length $(\mathrm{mm})$

$N$ : Roll rotating speed $\left(\mathrm{s}^{-1}\right)$

$\Delta R$ : Depth of grinding roll $(\mu \mathrm{m})$

$t_{g}$ : Grinding time (s)

$V$ : Worn volume of grinding wheel $\left(\mathrm{mm}^{3}\right)$

$V_{R}:$ Roll peripheral speed $(\mathrm{m} / \mathrm{min})$

$W$ : Contact width of grinding wheel $(\mathrm{mm})$

$w_{g}$ : Worn depth of grinding wheel $(\mu \mathrm{m})$.

The relationship between grinding characteristics, pressing force of the grinding wheel and roll peripheral speed is explained below:

Figure 6 shows the data obtained from grinding tests. Here, the pressing force of the grinding wheel is expressed as the pressing force per contact length of the grinding wheel, which can be expressed as follows;

$$
P=F / l
$$

where, $F$ : Pressing force of grinding wheel $(\mathrm{N})$

$l$ : Length of contact (mm)

$P$ : Unit pressure of grinding wheel $(\mathrm{N} / \mathrm{mm})$.

And other main conditions include:

Grinding wheel: GC320 K8V

Offset value: $60(\mathrm{~mm})$

Pressing angle: $8.73 \times 10^{-3}(\mathrm{rad})$.

The grinding capability $v_{g}$ increases as the unit pressure $P$ increases, and $v_{g}$ is not greatly affected by the roll peripheral speed.

The grinding ratio $G$ decreases as the unit pressure $P$ increases, and the faster the roll peripheral speed, the greater it becomes. For the roll surface roughness, no significant change could be seen due to the unit pressure or the roll peripheral speed, and the roughness remained more or less in the range of 0.5 to $0.8 \mu \mathrm{m}$.

\section{Principles and Accuracy of Measurement by OPM}

\subsection{Principles and Features of OPM Measurement}

Figure 7 outlines the configuration of the OPM system. The system employed for the detection of roll profile is: several units of ultrasonic displacement meters are installed on the Grinding Wheel Mount (GWM) of the ORG to detect distances from the roll surface and to measure roll profile using the traversing mechanism (stroke: about $300 \mathrm{~mm}$ ) of the GWM which operates in the axial direction of the roll.

Operations of this measuring system are outlined below:

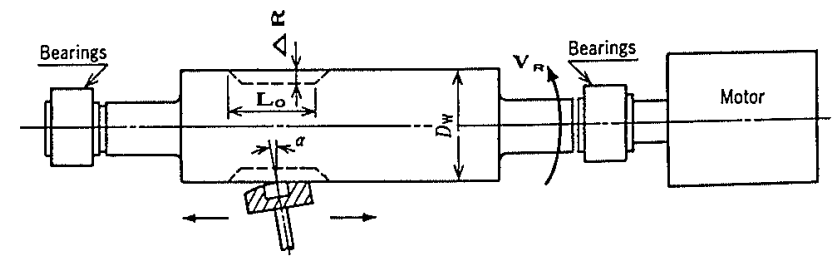

Fig. 5. Evaluation method for grinding characteristics. 
1) Detection of distance from the roll surface by means of ultrasonic displacement meters

2) Measurement of changes in distance in the axial direction of the roll

3) Detection of errors in motion of the GWM as a rigid body

4) Correction of measured values in item 2)

5) Tracing local roll profiles

6) Tracing overall roll profile.

The data processing sequence mentioned above is outlined in Fig.8. As this figure shows, the three-point straightness measuring system configurated at both ends of the GWM can help the correction of measurement errors which may be caused by changes in the relative positional relation between the ultrasonic displacement meter and the roll, ${ }^{1,2)}$ including errors in motion of the GWM and rotational deviation of roll, so that a true roll profile can be obtained with high accuracy.

As shown in Fig.7, another ultrasonic displacement meter is provided to correct measurement errors caused by changes


Fig. 6. Basic characteristics of ORG.

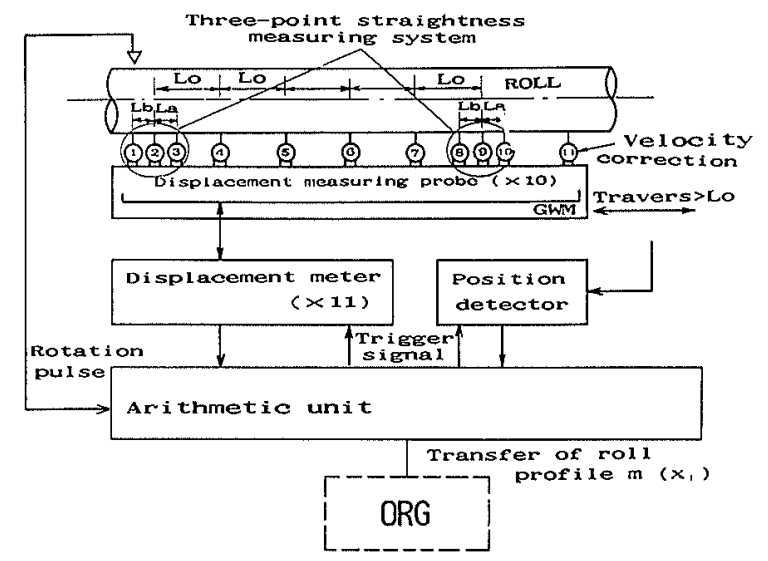

Fig. 7. Outline of OPM. in sonic velocity due to variation in water temperature.

\subsection{Accuracy of Measurement}

Using a pilot testing apparatus of actual machine size, a measurement test was performed. A test roll processed beforehand on a grinding machine to have the stepped roll profile shown in Fig.9 was used as a specimen to measure the roll profile.

The results of measurement are outlined in Fig.10. Figure 10(a) shows errors in straight motion of both ends of the GWM obtained by means of the three-point straightness measuring system. Figure 10(b) shows the roll profile traced after correction of the measurement errors of each ultrasonic displacement meter caused by the errors in straight motion. The traced roll profile is a close approximation to the shape of the test roll.

\section{ORG Feedback Grinding System}

An ORG equipped with an OPM can create an arbitrary profile of the roll as assembled in a mill by grinding it on the basis of the roll profile data taken by the OPM; this grinding is hereafter referred to as feedback grinding. A new feedback grinding algorithm has been developed to enable the ORG to grind a roll to any profile (Fig.11).

First, the area to be ground is determined from the dif-

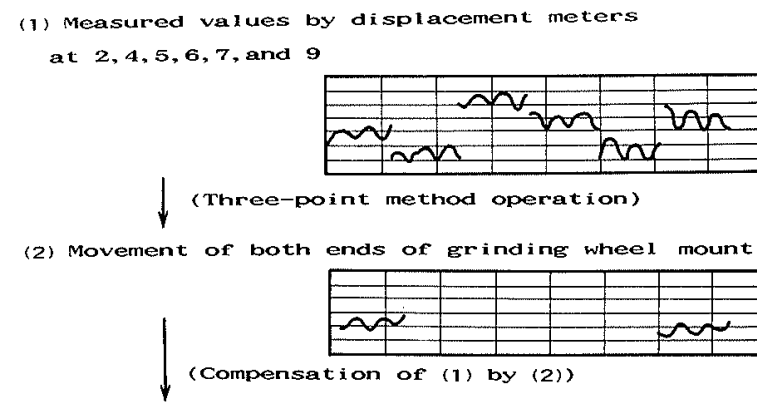

(3) True partial profile
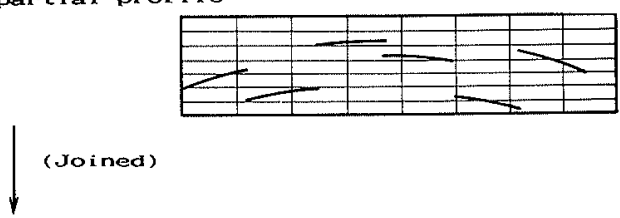

(4) Overall roll profile

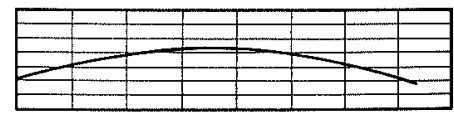

Fig. 8. Outline of data treatment procedure.

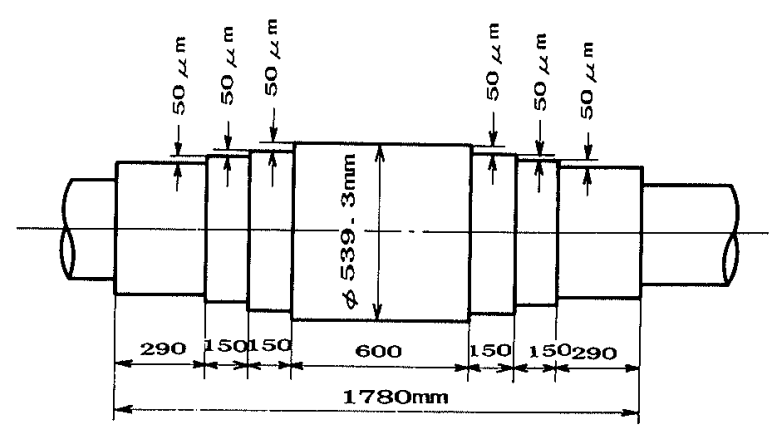

Fig. 9. Shape of test roll. 


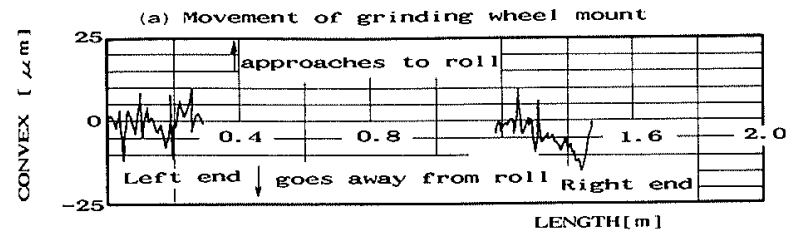

(b) Roll profile

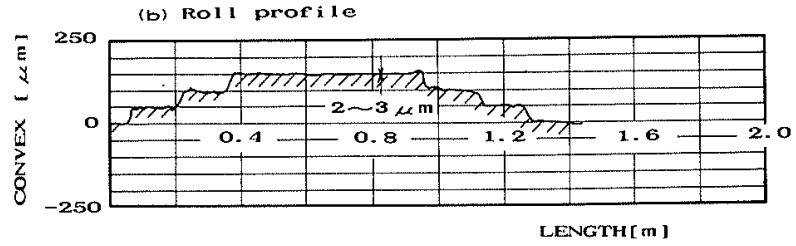

Fig. 10. Measurement results of roll profile.

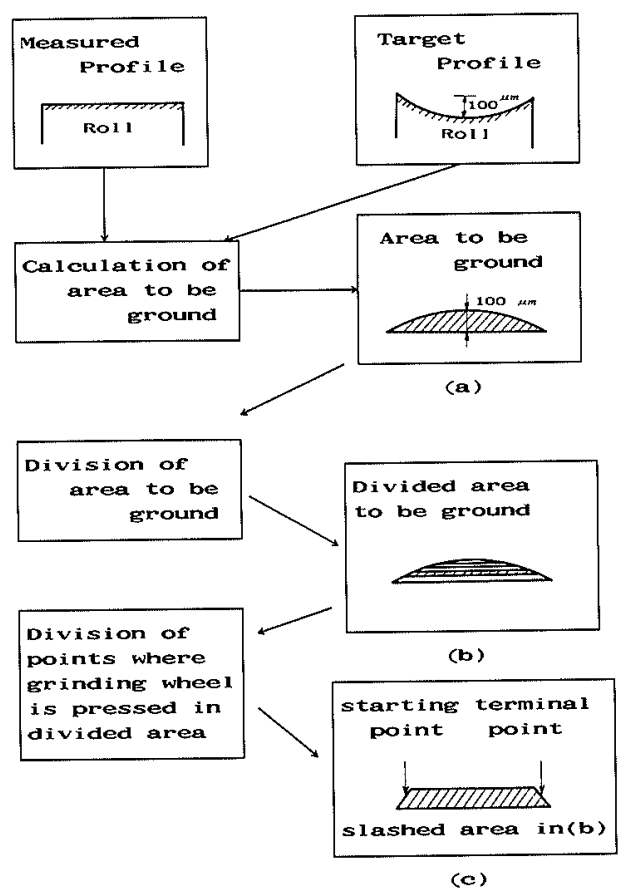

Fig. 11. Feedback grinding algorithm.

ference between the measured roll profile and the target roll profile. Figure 10(a) shows the area to be ground in a flat roll when its target profile is a concave crown of $100 \mu \mathrm{m}$. The area to be ground is divided into the amount of roll metal to be ground off by each oscillation, as shown in Fig.10(b). Each division is regarded as the area to be ground by the ORG when it makes one oscillation, and this area approximates to a trapezoid. The middle points of the sides of this trapezoid are defined as the starting and terminal points of grinding. The grinding wheel is pressed to the roll between these two points. This action of the grinding wheel is repeated by the number of divisions necessary to get the target roll profile.

Next, in order to confirm the validity of the feedback grinding system we developed, experiments were performed using test equipment.

Figure 12 shows the results of the experiments assuming an actual rolling process. In place of wear of the roll due to rolling, a step of $7.5 \mu \mathrm{m}$ was made over a width of $1200 \mathrm{~mm}$ by the ORG, and then, feedback grinding was done to flatten

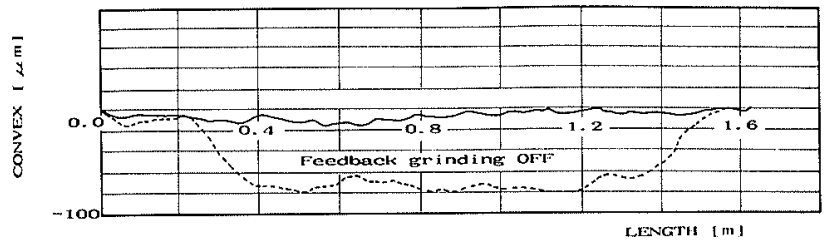

Fig. 12. Effectiveness of feedback grinding.

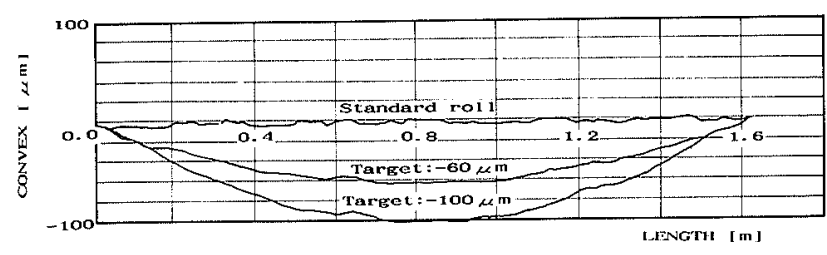

Fig. 13. Results of roll crown forming test.

the roll. The solid line shows the result when this operation was repeated 7 times. The broken line shows the result when a similar operation was done without feedback grinding. These results indicate that the feedback grinding produces a flat profile of roll without the sloping steps which occur when no feedback grinding is performed.

Figure 13 shows the results of grinding flat rolls to rolls with a concave crown of 60 and $100 \mu \mathrm{m}$ like the target profiles; this is done to verify the ORG's capability to grind rolls to optional profiles. High accuracy of $\pm 6 \mu \mathrm{m}$ of the target profiles was obtained.

\section{Conclusion}

We designed a non-driven cup type on-line roll grinder (ORG) capable of smoothing a work roll on line which relaxes the restriction on the rolling schedule of hot strip mills, and examined its basic grinding characteristics using test apparatus of actual size.

The results revealed the excellent basic performance of the ORG in grinding capacity, life of the grinding wheels and roughness of the finished roll surface, as well as stability in the grinding operation with no welding or dulling of the grinding wheels.

Further, an on-line roll profile meter capable of measuring the profile of a revolving roll without contact was fabricated to improve the grinding accuracy of the ORG.

We then developed an on-line roll grinding system consisting of ORGs with on-line profile meters for accurate feedback grinding of a roll to the required profile. We made clear the grinding accuracy of this system by experiments.

\section{REFERENCES}

1) Y. Kakino, H. Taniguchi, M. Yasui and K. Uesugi: J. Jpn. Soc. Precision Eng, 48 (1982), No.2, 239.

2) H. Shimazutsu and Y. Kakino: JSPE Conference Autumn, I19 (1988).

\section{Appendix}

Method of analysis for contact conditions of the grinding wheel in the non-driven cup-type grinding wheel system.

Using the center of the grinding wheel surface as a home point, extend $z$ axis vertical to the grinding wheel surface, $y$ 
axis on a line at which a plane perpendicular to the roll axis intersects the grinding wheel surface, and $x$ axis vertical to $y$ and $z$ axis. (See Fig.A-1)

Given that the distance between $z$ axis and the roll axis is $H$, and the angle formed by $z$ axis and the plane perpendicular to the roll axis is $\alpha$, the arrangement illustrated by the arrow from y axis is obtained. Then, let the coordinates, at which the roll surface starts biting against the grinding wheel, be $(x, y)=\left(X_{0}, H\right)$.

$$
\delta(x, H)=\left(x-X_{0}\right) \tan \alpha
$$

If the biting quantity at $(x, y)$ coordinates is denoted as $\delta$ $(x, y)$, the following equations are obtained.

$$
\begin{array}{r}
\delta(x, y)=\delta(x, H)-R\left\{1-\cos \left(\sin ^{-1} \frac{|H-y|}{R}\right)\right\} \\
=\left(x-X_{0}\right) \tan \alpha-R\left\{1-\cos \left(\sin ^{-1} \frac{|H-y|}{R}\right)\right\} \\
\ldots \ldots \text { (A-2) } \ldots \ldots \text {. . . . }
\end{array}
$$

$$
\begin{aligned}
\delta(r, \varphi) & =\left(r \cos \varphi-X_{0}\right) \tan \alpha \\
& -R\left\{1-\cos \left(\sin ^{-1} \frac{|H-r \sin \varphi|}{R}\right)\right\} \ldots .
\end{aligned}
$$

where $X_{0}$ is determined by contact conditions set up between the boundary bite line made by the grinding wheel and the roll, $\psi(x, y)=0$, and the inside diameter of the grinding wheel, $x^{2}+y^{2}=r_{G}{ }^{2}$. If the contact point is expressed as $\left(x_{0}\right.$, $\left.y_{0}\right)$, the relation becomes:

$X_{0}=x_{0}-\frac{R}{\tan \alpha}\left\{1-\cos \left(\sin ^{-1} \frac{\left|H-y_{0}\right|}{R}\right)\right\} \ldots$

In this condition, when the grinding wheel follows the rotation of the roll, the contact point (line) made by the grinding wheel and the roll becomes one where max. biting quantity $\delta_{m}(r)$ is given on a concentric circle of the grinding wheel. Given that the angle at the time is $\varphi_{m}$, the relation is:

$$
\max \{\delta(r=\text { const, } \varphi)\}=\delta\left(r, \varphi_{m}(r)\right)=\delta_{m}(r) \ldots
$$

Let the rotation speed of the grinding wheel, which turns into follow-up rotation with the roll owing to the roll surface velocity $V_{R}$, be $n$. The grinding wheel velocity $V_{G}(r)$ at the point of radius $r$ becomes:

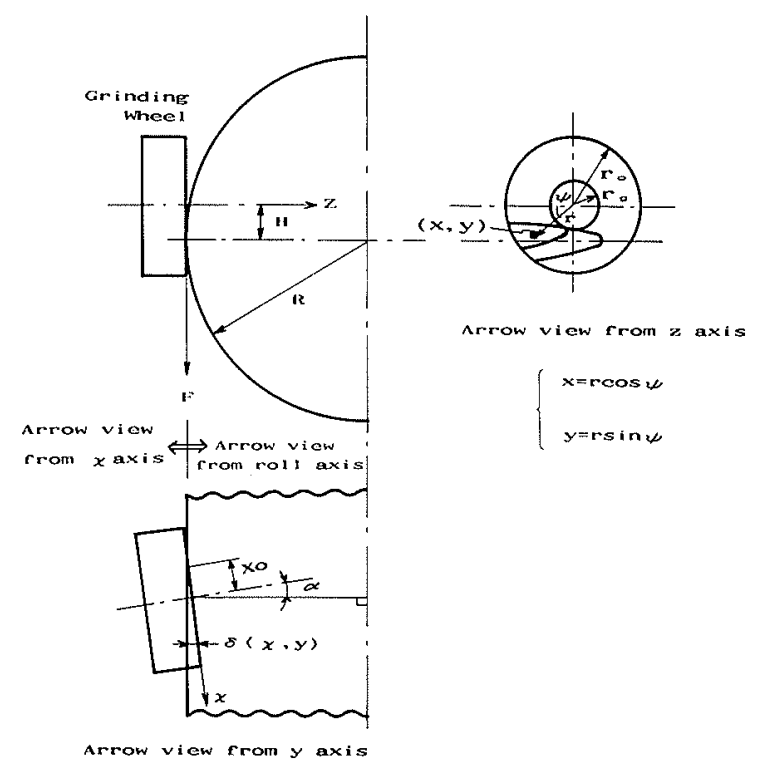

Fig.A-1. Relation between the grinding wheel and roll.

$$
V_{G}(r)=2 \pi r n \ldots \ldots \ldots \ldots \text { (A } 6 \ldots \text {. }
$$

Then, slipping will occur due to the difference between the roll velocity and the grinding wheel velocity. The slipping velocity $V_{S}(r)$ is obtained by Eq.(A-7).

$V_{s}(r)^{2}=V_{R}^{2}+V_{G}(r)^{2}-2 V_{R} \cdot V_{G}(r) \cdot \cos \varphi_{m}(r) \ldots .(\mathrm{A}-7)$

A friction force is applied in the slipping direction, and the torque due to the peripheral speed component of the grinding wheel, when accumulated over the whole range of the contact line, becomes equal to the torque applied to the grinding wheel axis. Therefore, if the unit pressure and the friction coefficient are kept constant over the whole range of the contact line, the following equation is obtained.

$$
\int_{r_{G}}^{r_{0}} \frac{V_{R} \cos \varphi_{m}(r)-V_{G}(r)}{V_{s}(r)} r d r=\tau \ldots \ldots
$$

where torque $\tau$ is zero in the case of follow-up rotation, and the rotation speed of the grinding wheel $\mathrm{n}$ can be determined, so as to establish Eq.(A-8). On the other hand, the slipping direction $y(r)$ is determined as follows:

$$
\cos \psi(r)=\frac{V_{R}^{2}+V_{s}(r)^{2}-V_{G}(r)^{2}}{2 V_{R} \cdot V_{s}(r)} \ldots \ldots
$$

